\title{
The effects of shot peening on subsurface layer properties and fatigue performance of case-hardened 18 CrNiMo7-6 steel
}

\author{
Hsin Shen Ho, Junfeng Xie, Lingli Sun, Penghui Niu, and Erliang Zhang* \\ School of Mechanical Engineering and Henan Key Engineering Laboratory of Anti-Fatigue Manufacturing Technology, Zhengzhou \\ University, Science Road 100, 450001 Zhengzhou, China.
}

\begin{abstract}
The present study is conducted with a dual-aim; firstly, examine the effect of several single shot peening conditions on the subsurface layer properties and fatigue performance of the case-hardened 18CrNiMo7-6 steel. By carrying out the subsurface integrity analysis and fatigue testing, the underlying relationships among the peening process, subsurface layer property and fatigue performance are investigated, the way peening conditions affect the fatigue life and its associated scatter for the casehardened $18 \mathrm{CrNiMo} 7-6$ steel is quantitatively assessed.
\end{abstract}

\section{Introduction}

High strength steels are massively used in the aeronautical and automotive applications for their highloading capacity. With the increasing demand for high reliability products, the dual properties of high strength and high ductility are expected for such steel materials to give a longer service lifetime of engineering machinery. This motivates the design of a new class of material, referred to as gradient nanostructured (GNS) high strength steel [1]. As fatigue failures generally occur on the material surface and propagate into the interior, a structural architecture comprising a GNS subsurface region and a coarse-grained interior is considered optimal for enhanced fatigue behavior. The GNS subsurface layer can be formed through surface strengthening treatments by means of mechanical method such as shot peening (SP), which entails impacting a surface with small, round and hard particles with force sufficiently high to create localized plastic deformation for the formation of a deep work-hardened and compressed subsurface layer in metals and alloys [2]. Despite the development of many new types of peening techniques such as laser shot peening and ultrasonic shot peening [3-4], conventional shot peening method remains one of the most important means in the industrial production due to its high flexibility and productivity, low cost and environmental friendliness. For these reasons, shot peening process is of particular interest in the present work.

Mechanical methods can be combined with other surface strengthening treatments such as thermochemical methods for further improvement in fatigue strength and fatigue life of steel components [5-7]. However, the hybrid process cannot always be advantageous to the application of steels. For instance, it is shown in Ref. [6] that when both carbo-nitrided gear and carbo-nitrided plus peened gear made of AISI 4130 steel are subjected to contact fatigue testing, fatigue damages, which are ought to be in different modes, are found to occur after about the same testing time for both types of methods. This could most probably be a consequence of the use of inappropriate shot peening condition, the extreme shot bombardment on the surface can cause roughness increment and flaw occurrence, and therefore outweigh the beneficial effect brought by the hybrid process.

Thus, understanding of how the mechanical process parameters affect the heat-treated surface and subsurface layer properties, which in turn influence the fatigue performance is the ultimate aim of the present work. To tackle this issue, high strength $18 \mathrm{CrNiMo} 7-6$ steel, widely employed in high-speed and heavy-duty gear applications, is selected as the target material. The carburizing and shot peening are respectively selected as thermo-chemical and mechanical methods since they are the versatile surface strengthening treatments commonly used in the automotive industry. In the present work, a few single shot peening conditions with different Almen intensities and shot diameters are carried out on 18CrNiMo7-6 steel posterior to the carburizing process. By carrying out the surface and subsurface layer property analysis and fatigue testing, this work is aimed to establish qualitative inter-relationships between peening process conditions, surface and subsurface layer properties and fatigue performance.

\section{Material and methods}

\subsection{Gear material}


In the present study, the target material is $18 \mathrm{CrNiMo} 7-6$ steel with its chemical composition summarized in Table 1. All the specimens are carburized in a controllable gas carburizing furnace, then subsequently quenched in oil to room temperature, and finally followed by tempering and cooling in air. The thermo-chemical conditions are utilized in agreement to gear heat treatment standard ANSI/AGMA B89-2004 [8].

Table 1. Chemical composition of 18CrNiMo7-6.

\begin{tabular}{|c|c|}
\hline Element & Composition (wt \%) \\
\hline $\mathrm{C}$ & $0.15-0.21$ \\
\hline $\mathrm{S}$ & $\leq 0.035$ \\
\hline $\mathrm{Si}$ & $\leq 0.40$ \\
\hline $\mathrm{Mn}$ & $0.50-0.90$ \\
\hline $\mathrm{P}$ & $\leq 0.025$ \\
\hline $\mathrm{Cr}$ & $1.50-1.80$ \\
\hline $\mathrm{Ni}$ & $1.40-1.70$ \\
\hline $\mathrm{Mo}$ & $0.25-0.35$ \\
\hline $\mathrm{Fe}$ & balance \\
\hline
\end{tabular}

\subsection{Shot peening treatments}

The shot peening treatment is performed with the air blast shot peening machine. The specimens are treated by shot peening with different intensities and shot diameters. The intensities of peening are measured by the arc height of Almen specimens, varying from 0.25 $\mathrm{mmA}-0.45 \mathrm{mmA}$. Cast steel balls with diameters of $0.3 \mathrm{~mm}$ and $0.6 \mathrm{~mm}$ are selected as shot blasting media in accordance to ISO 26910-1 [9]. The coverage of shot peening is $200 \%$ for all peening processes, which is obtained by doubling the exposure time needed to achieve full coverage (100\%). The different shot peening configurations of immediate interest are presented in Table 2.

Table 2. Shot peening parameters for case-hardened 18CrNiMo7-6 steel.

\begin{tabular}{|c|c|c|c|}
\hline Variant & $\begin{array}{c}\text { Shot diameter } \\
(\mathbf{m m})\end{array}$ & $\begin{array}{c}\text { Coverage } \\
\mathbf{( \% )}\end{array}$ & $\begin{array}{c}\text { Almen } \\
\text { intensity } \\
(\mathbf{m m A})\end{array}$ \\
\hline SP0 & - & - & - \\
\hline SP1 & 0.3 & 200 & 0.25 \\
\hline SP2 & 0.6 & 200 & 0.25 \\
\hline SP3 & 0.6 & 200 & 0.45 \\
\hline
\end{tabular}

\subsection{Measurement methods}

The cross-section of the specimen is first mechanically polished using standard metallographic techniques, then chemically-etched by $8 \%$ Nital. The cross-section microstructure of the specimen is subsequently investigated by scanning electron microscopy (SEM) using Zeiss Auriga FIB-SEM at room temperature.

The microhardness is measured along the depth of the cross-section of the specimen using a Vickers microhardness tester with a load of $200 \mathrm{~g}$ and a holding time of $10 \mathrm{~s}$.

The residual stress along the depth of the crosssection of the specimen is measured by the X-ray stress analyzer (LXRD, Proto, Canada) using $\mathrm{Cr} \mathrm{K} \alpha$ radiation and martensitic $\{211\}$ crystalline plane. The voltage and current are respectively $30 \mathrm{kV}$ and $25 \mathrm{~mA}$. The measured interference peaks are evaluated by the $\sin 2 \psi$ method with the diffraction angle $(2 \theta)$ varying from $-45^{\circ}$ and $45^{\circ}$.

The surface state of the specimen is examined by Veeco Wyko NPFLEX optical profiler. The measured surface topography is characterized by amplitude surface roughness parameters in agreement to ISO 25178-2012 [10].

\subsection{Fatigue testing}

Following the set-up and procedure for conducting the SAE single tooth bending fatigue test using a servohydraulic fatigue testing machine [11], the applied cyclic fatigue load is 0.82 of the yield stress of the bulk material, the stress ratio $R=0.01$ and the nominal cyclic frequency is $89 \mathrm{~Hz}$ at room temperature. Each test series includes six gear tooth specimens. All the specimens are tested until occurrence of fracture, else the tests are terminated at $3 \times 10^{6}$ cycles.

\section{Results and discussions}

\subsection{Microstructure}

In Figure 1, the cross-sectional surface by SEM is presented for the carburized specimen with different microstructures.

Fig. 1. Cross-sectional SEM of SP0; the microstructure of (a) top surface region and (b) bulk material.

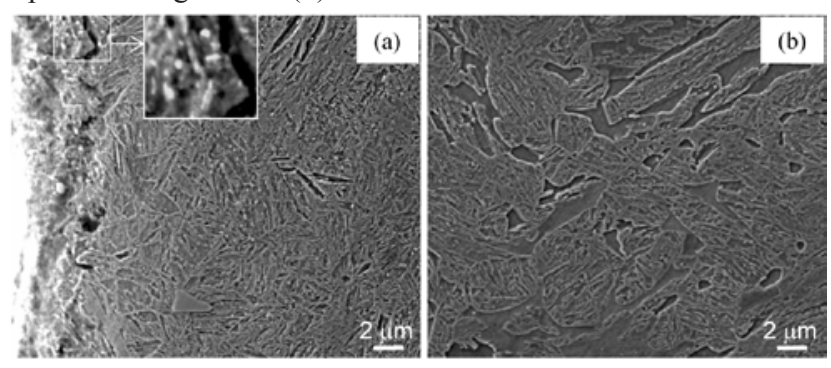

Figure 1 shows that three distinct regions can be recognized: the first region, a very thin white carbon 
oxide layer which is hard and brittle with the thickness lying between a few microns with the presence of the pores, carbides and micro-cracks within this oxidized layer; the second region, the case-hardened zone which consists mainly of martensite microstructure with a very small quantity of retained austenite and finely dispersed undissolved spherical carbide particles; and the third region, the bulk material, i.e. the substrate without any evidence of microstructural change.

Figure 2, illustrating SEM micrographs of the crosssection of $18 \mathrm{CrNiMo} 7-6$ steel subjected to the combined method, shows that shot peening performed after carburizing can not only suppress the porous structure at the outer oxidized layer but also change the microstructure of the near surface region of $18 \mathrm{CrNiMo} 7-$ 6 steel.

Fig. 2. Cross-sectional SEM of SP3 specimen; the microstructure of (a) top surface region and (b) bulk material.

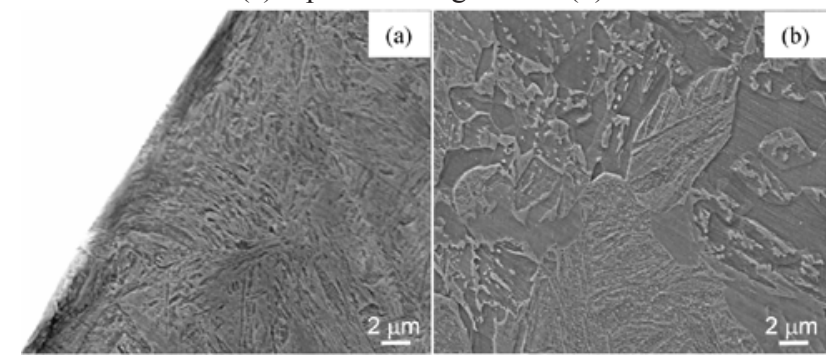

In fact, shot peening is a process which consists of projecting high-velocity shot particles by the action of an external force. So, when the external force reaches the critical stress required for dislocation movement, dislocation slip is generated and well-defined slip band structure is therefore formed. On the same slip plane, when the amount of dislocations impeded at the grain boundaries increases, the pile-ups of dislocations are formed [12]. Consequently, the phenomenon of stress concentration can easily occur in the vicinity of grain boundaries due to the heavy accumulation of the dislocations pile-ups against the boundaries. When a critical stress value is reached, the grain boundaries are destroyed and a high-density nano-scale deformation twins is formed. The intensive interactions between twin boundaries and dislocations may then lead to subsequent transformation of two-dimensional twin lamellae structures into three-dimensional nanograins with their boundary characteristics lying in the form of low-angle and high-angle. Herein, there are a considerable fraction of low-angle grain boundaries and a high density of dislocations resided in the non-equilibrium high-angle grain boundaries [13]. In addition to plastic deformationinduced grain refinement, strain-induced phase transformation is another mechanism by which nanosurface forms during shot peening. The strain-induced nucleation of martensite transformation can take place more dominantly at higher-energy grain boundaries due to their atomic structures and energies. Besides, the strain localization bands and deformation twins that accumulate high strain energy storage could also promote martensitic transformation. All these are elaborated here to show that the principal microstructural changes induced by shot peening consist mainly of plastic deformation-induced grain refinement and straininduced phase transformation.

\subsection{Hardness}

Figure 3 presents the distributions of in-depth microhardness of all specimens. For SP0 carburized specimen, the maximum microhardness appears on the surface, then gradually decreases with increasing depth and finally reaches a stabilized value, which is wellaccepted to be a consequence of the declination of the carbon content from the surface to the center. Meanwhile, when shot peening is performed on casehardened steel, regardless of shot peening condition, a similar trend of the microhardness distribution is also observed, which is generally found to be attributed to the shot peening-induced reduction of plastic deformation from the outer surface to the center.

Fig. 3. Microhardness distribution curves of all surface treated specimens.

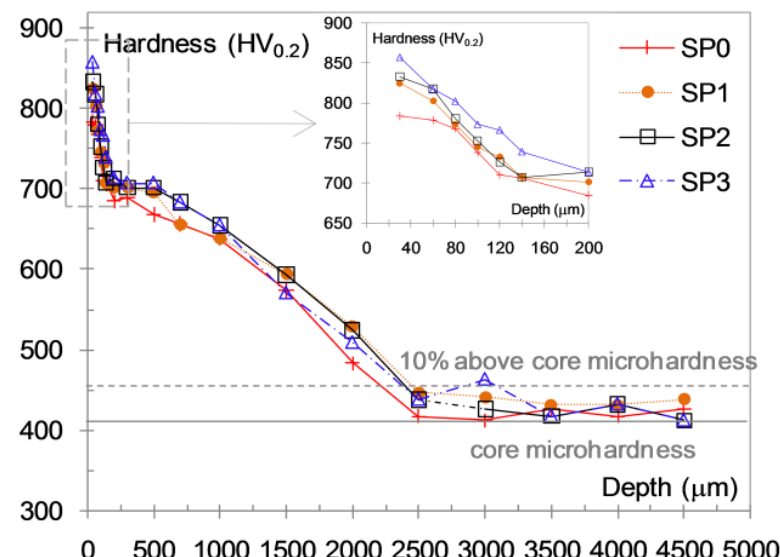

Case depth after thermo-chemical treatments is very often considered as a matter of convention. When fatigue characteristics are regarded, a microhardness value of $10 \%$ above the core microhardness is generally used to characterize the case depth [7]. The case depth is approximated to be $\sim 2250 \mu \mathrm{m}$, as exhibited in Figure 3.

The hybrid process of carburizing and shot peening has caused an increment in surface microhardness from the top surface up to a limited depth approximated to be $\sim 140 \mu \mathrm{m}$. Compared to the maximum surface microhardness of carburized SP0 specimen (784 $\left.\mathrm{HV}_{0.2}\right)$, that of carburized and peened are estimated to increase by $9.3 \%$ for SP3 specimen $\left(857 \mathrm{HV}_{0.2}\right)$, by $6.3 \%$ for SP2 specimen $\left(833 \mathrm{HV}_{0.2}\right)$, and by $5.2 \%$ for SP1 specimen $\left(825 \mathrm{HV}_{0.2}\right)$, which can be attributed to the presence of shot peening-induced structure consisting mainly of the martensitic state. The increase in the maximum surface microhardness caused by the increase of shot diameter is quite comparable to that resulted by the increase of Almen intensity. Indeed, the values of the maximum surface microhardness which are found to increase by $\sim 2.9 \%$ with the increment of the Almen intensity and by $\sim 1.0 \%$ with the increasing of the shot diameter shows that the maximum surface microhardness-increment is 
restricted to some extent, which infers that the plastic deformation of $18 \mathrm{CrNiMo} 7-6$ steel subjected to the combined processing of shot peening and carburizing has reached a critical condition.

The results hereby obtained show that the thermochemical surface treatment is kind of advantageous in terms of microhardness distribution compared to mechanical surface treatment, in accordance with the results obtained in Ref. [14].

\subsection{Residual stress}

In Figure 4, the residual stress in-depth distributions of all the surface treated specimens are depicted. It is shown that in the range of testing, all the specimens have similar trend of obvious compressive residual stress distribution; the top surface compressive residual stress first increases to a maximum (denoted as maximum compressive residual stress), then decreases gradually along the depth direction of the hardened layer and remains constant thereafter.

Fig. 4. Residual stress distribution curves of all surface treated specimens

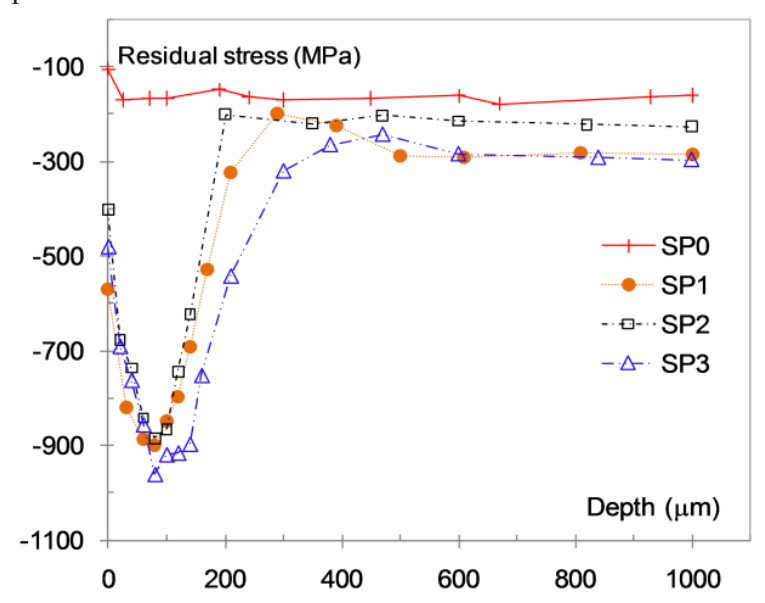

As can be seen from the Figure 4, the increment of the process-induced top surface compressive residual stress and maximum compressive residual stress are much more important for the combined processing of carburizing and shot peening than the individual carburizing process only. The observation shows that shot peening process is highly beneficial in generating compressive residual stress as compared with the carburizing process.

Regardless of the shot peening process parameter, the values of the compressive residual stress are exhibited to be lower at the top surface than at the peak position and the maximum compressive residual stresses are revealed to be located in the subsurface region at the depth of $\sim 90 \mu \mathrm{m}$. The former is found to be resulted from the counteracting effects of not only the tensile residual stress but also the high surface roughness produced by prior machining. And the latter suggests that the steel material which undergoes plastic deformation has most probably reached a critical plastic deformation limit, and thus, the continuous impingement of the shot particles would not further deepen the compressed subsurface region.

In Figure 4, the values of the compressive residual stress observed at the top surface and peak position are increasing with the increase of Almen intensity. This is because the increase in Almen intensity, which involves the increase in shot velocity, produces more kinetic energy and thereby, induces a greater amount of plastic deformation on the hardened surface region, and as a consequence the compressive residual stress is elevated. However, with an increase of the shot diameter, the top surface and maximum compressive residual stresses are on the decrease. This is because when larger diameter shots are projected on the surface of the specimen with a small-scale finite kinetic energy, a larger impact area is created, resulting thereby in a reduction of equivalent plastic strain and consequently, the compressive residual stress is lowered.

It can be seen at the top surface region that the effect of shot diameter is more significant than that of Almen intensity on the compressive residual stress; the decrease of shot diameter induces an increase of compressive residual stress by $42.0 \%$ while the increase of Almen intensity causes an increase of compressive residual stress by only $19.7 \%$. It can also be observed from Figure 4 that the values of the compressive residual stress at the peak position $(\sim 90 \mu \mathrm{m})$ appear to be less severely affected by shot diameter rather than Almen intensity; the increase of Almen intensity leads to an increase in compressive residual stress by $8.5 \%$ but the compressive residual stress grows by only $1.8 \%$ with the decrease of shot diameter.

\subsection{Roughness}

In what follows, the roughness characterization results are presented. The arithmetic mean height parameter $\left(S_{\mathrm{a}}\right)$, which is a commonly used roughness parameter for characterization of measured surface texture, is used to discuss the surface states of treated specimens. With the $S_{\mathrm{a}}$ value of $\sim 2.51 \mu \mathrm{m}$, the surface of the carburized specimen can be considered to be rather rough. In this instance, the roughness can be ascribed to the roughness left by machining (c.f. Figure 5(a)) but also to the formation of the oxide layer produced by carburizing (c.f. Figure 1(a)).

Table 3. $S_{\mathrm{a}}$ values of all surface treated specimens.

\begin{tabular}{|c|c|}
\hline Variant & $\boldsymbol{S}_{\mathbf{a}}(\boldsymbol{\mu} \mathbf{m})$ \\
\hline SP0 & 2.51 \\
\hline SP1 & 1.97 \\
\hline SP2 & 2.69 \\
\hline SP3 & 1.89 \\
\hline
\end{tabular}

It can be seen from Table 3 that the magnitude of roughness due to shot peening induced at the caburized 
specimen strongly depends on the applied shot peening conditions. When the Almen intensity is low, the impact of shot peening using smaller shot blasting particles is equivalent to the effect of surface polishing and as a consequence, surface roughness is reduced; the surface roughness of SP1 specimen (with $S_{\mathrm{a}} \approx 1.97 \mu \mathrm{m}, c . f$. Figure 5(b)) is exhibited to decrease by $21.5 \%$ compared to that of SP0 specimen (with $S_{\mathrm{a}} \approx 2.51 \mu \mathrm{m}, c$.f. Figure $5(\mathrm{a}))$. Though, the use of smaller shot media is unable to provide sufficient plastic deformation that could modify the surface texture left by the heat treatments and machining operations (c.f. Figure 5(b)). If shot peening is performed using larger shot blasting particles, the surface roughness is increased; the roughness of SP2 specimen (with $S_{\mathrm{a}} \approx 2.69 \mu \mathrm{m}$, c.f. Figure $5(\mathrm{c})$ ) is found to be $7.2 \%$ higher than that of SP0 specimen. Though, the use of larger shot media producing a higher level of plastic deformation would allow obtaining a more evenly distributed texture (c.f. Figure 5(c)).

Fig. 5. Surface topographies at the root surface of (a) SP0, (b) SP1, (c) SP2 and (d) SP3.

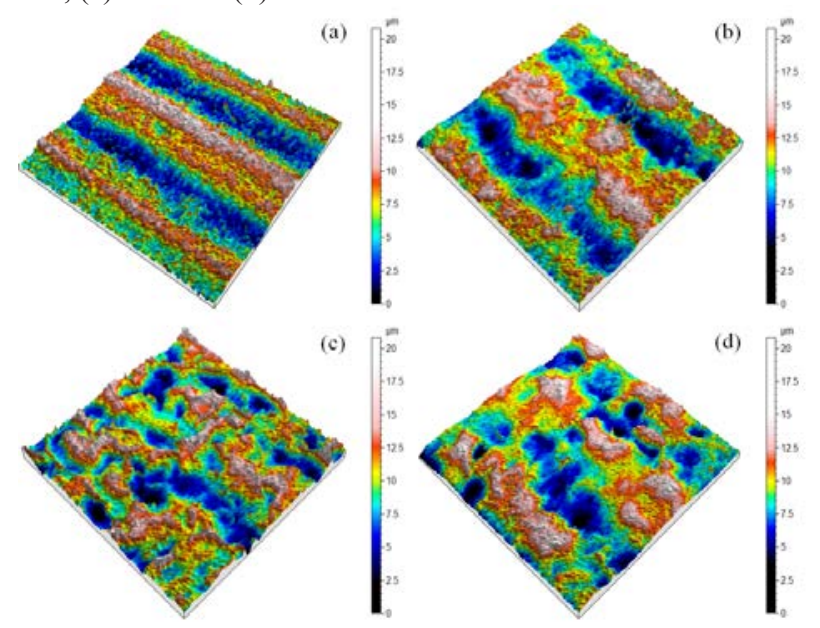

With increasing Almen intensity from $0.25 \mathrm{mmA}$ to $0.45 \mathrm{mmA}$, the surface state of the specimen is improved and thus, the surface roughness is reduced; the $S_{\mathrm{a}}$ value of SP3 specimen $(\approx 1.89 \mu \mathrm{m}$, c.f. Figure $5(\mathrm{~d}))$ is approximated to be $24.7 \%$ less than that of SP0 specimen. This can be explained by the fact that the very hard surface layer has been subjected to the "intense" shot peening process. It is worth mentioning that using a high Almen intensity at $200 \%$ coverage can be interpreted as if every portion of the hard surface has been treated with very high impact energy shot blasting particles for at least two times. Thereby, less plastic deformation is generated as the surface roughness is hardly altered and consequently, the surface roughness is considerably being lowered. This observation is found to be in accordance with the results exhibited in the literature [10].

\subsection{Fatigue test data}

The fatigue tests are carried out to examine the fatigue performance of all the surface treated specimens. In Figure 6 , the fatigue lives $\left(N_{\mathrm{f}}\right)$ of these surface treated specimens are depicted. $N_{\mathrm{f}}$ for case-hardened specimens is determined in the range of $14.8-57.9 \times 10^{3}$ cycles. It is observed in the figure that the shot peening process has considerably improved the fatigue lives of casehardened specimens, which is attributed to the principal effects induced by shot peening, e.g. microstructure refinement, retained austenite reduction, microhardness amelioration, compressive residual stress generation and surface roughness alteration. It is worth noting that the trend of fatigue life improvement is highly dependent on the surface and subsurface layer properties of 18CrNiMo7-6 steel, which in return, are directly influenced by the shot peening conditions.

Fig. 6. Bending fatigue lives of surface treated specimens.

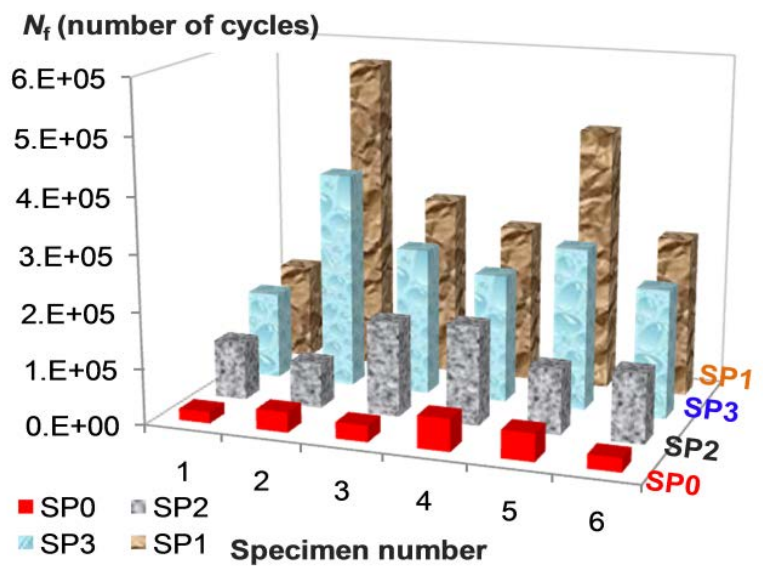

It is clearly shown in Figure 6 that $N_{\mathrm{f}}$ for SP2 specimens is the lowest and it is improved with an increment in the Almen intensity, as is exhibited for SP3 specimens. This considerable improvement is solely a consequence of the presence of deeper compressed work-hardened subsurface layer with ameliorated surface roughness in SP3 specimens. Meanwhile, SP1 specimens are found to have the highest $N_{\mathrm{f}}$ in spite of having moderate work hardening and compressive residual stress. The marked increase in $N_{\mathrm{f}}$ for SP1 specimens can be related to the fact that the magnitude of the surface roughness is the lowest among all peened specimens (c.f. Table 3). Nevertheless, the dispersion degree of the fatigue life of the SP1 specimen is found to be rather high, i.e. the repeatability rate of the SP1 specimen test sequences is rather low. This might be a consequence of the presence of the scatter in fatigue strength endowed by the surface and subsurface layer properties, which is unable to completely cause a shift in fatigue crack initiation site from a surface to subsurface location, and therefore cause the simultaneous occurrence of both surface and subsurface fatigue crack initiation in a fatigue testing series. This certainly intensifies the dispersion of the fatigue life.

\section{Conclusions}

In this paper, the effect of different shot peening conditions on the surface and subsurface layer properties, and the fatigue performance of case-hardened $18 \mathrm{CrNiMO} 7-6$ steel has been investigated. The analysis 
of the surface and subsurface integrity reveal that the subsurface region of the case-hardened 18CrNiMO7-6 steel can no further accumulate enormous localized plastic deformation during shot peening process as a consequence of the attainment of a critical limit of the plastic deformation for $18 \mathrm{CrNiMo} 7-6$ steel due to the presence of a very high dislocation density and carbon content induced by the prior carburizing process. Based on the assessment of fatigue performance, the interrelationships between peening process - subsurface layer property - fatigue performance are qualitatively established; shot peening application with lower intensity and smaller shots causing moderate subsurface layer properties results in an increase in both fatigue life and its associated scatter, while shot peening application with higher intensity and larger shots producing superior subsurface layer properties exhibits comparable estimate of fatigue life with decreased scatter in fatigue data.

Acknowledgement. The authors are grateful to National Natural Science Foundation of China - International Cooperation and Exchange Program (Grant No. 51650110502) and Henan Provincial Research Bureau (Grant No. 17A460025) for their financial support.

\section{References}

1. K. Lu, Science 345, 1455 (2014)

2. Y.K. Gao, X.R. Wu, Acta Mater. 59, 3737 (2011)

3. S. Huang, Y. Zhu, W. Gui, P. Peng, H.C. Qiao, X.G. Diao, P.K. Chu, J Mater. Eng. Perform. 25, 813 (2017)

4. V. Singh, M. Marya, J Mater. Eng. Perform. 25, 338 (2016)

5. Y. Lv, L.Q. Lei, L.N. Sun, Mater. Sc. Eng. A 658, 77 (2016)

6. A.C. Batista, A.M. Dias, J.L. Lebrun, J.C. Le Flour, G. Inglebert, Fatigue Fract. Eng. Mater. Struct. 23, 217 (2000)

7. F. Ashrafizadeh, Surf. Coat. Tech. 174-175, 1196 (2003)

8. ANSI/AGMA B89. Gear material and heat treatment manual (2004)

9. ISO 26910-1. Springs -- Shot peening - Part 1: general procedures (2009)

10. ISO 25178-2. Geometrical product specifications (GPS) -- Surface texture: areal -- Part 2: terms, definitions and surface texture parameters (2012)

11. R.W. Buenneke, M.B. Slane, C.R. Dunham, M.P. Semenek, M.M. Shea, J.E. Tripp, Gear single tooth bending fatigue test, SAE Technical Paper 821042 (1982)

12. S.M. Hassani-Gangaraj, K.S. Cho, H.J.L. Voight, M. Gugliano, C.A. Schuh, Acta Mater. 97, 105 (2015)

13. X.H. An, Q.Y. Lin, S.D. Wu and Z.F. Zhang, Mater. Res. Lett. 3, 135 (2015)
14. S.M. Hassani-Gangaraj, A. Moridi, M. Guagliano, A. Ghidini and M. Boniardi, Int. J. Fatigue 62, 67 (2014) 